\title{
Application of Remote Sensing and Geo-Statistical Analysis for Soil Salinity Monitoring in Tina Plain Area of Egypt
}

\author{
Gehan A.H. Sallam, Mohamed Embaby, Mohamed Nower
}

\begin{abstract}
In Egypt require to improve agricultural production to save food demand with increase population. Soil salinity is a significant attractive problem for agriculture in irrigated areas. As a result, monitoring of soil salinity is required for salinization control. One of the greatest challenges faced by Egypt's decision-makers is the acquisition of reliable integrated soil salinity information to introduce and recommendation of a simple approach to formulating a guideline for stakeholders. Saline affected areas are vast, making it extremely difficult to examine soil quality with field and laboratory data to provide reliable approach to forecast and monitor soil salinity. Objective of this paper is to research remote sensing and ArcGIS tools by Geo-Statistical Analyst techniques to map saline-sodic heavy clay soils of the Tina plain area in Egypt. Tina Plain characterizes a serious area for potential development of agricultural land in Egypt. Satellite images were downloaded by Landsat 8, Sentinel-2A, Sentinel-1, and Synthetic Aperture Radar C-band data were wont to map soil salinity within the area. By coefficient of correlation method were preformed, evaluated and compared of the Three models. The results revealed that the Sentinel-2A optical imaging satellite yielded the very best prediction performance. ArcGIS Geo-Statistical Analyst was also successfully wont to predict and map the saline-sodic heavy clay soils with a mistake percentage of about $4.28 \%$, which is taken into account as a minor error. generally, the study confirms that the Remote Sensing and ArcGIS Geo-Statistical Analyst are often considered by researchers and decision-makers as a credible, cost-effective, and time-controlled techniques to work out and predict the extension of soil salinity.
\end{abstract}

Keywords: Soil Salinity; Remote Sensing; Geo-statistical Analyst; ArcGIS.

\section{INTRODUCTION}

$\mathrm{O}$ ne of the reasons for problems is Soil salinity especially in the arid and semi-arid zones due to its negative outcomes on agricultural productivity and sustainable development. Saline soil conditions have a reduction resulted in the value and productivity of considerable areas of land throughout the world (1) Salinity problem managing to attenuate

Revised Manuscript Received on June 15, 2020.

* Correspondence Author

Gehan A.H. Sallam*, Associate Professor, Drainage Research Institute (DRI), National Water Research Center, Delta Barrages, Cairo Egypt. Email: gehanhakeem@hotmail.com

Mohamed Embaby, Researcher, National water research center, Cairo, Egypt. Email: m_moh1979@yahoo.com

Mohamed Nower, Associate Researcher, National water research center, Cairo, Egypt. Email: nower2020@gmail.com

(C) The Authors. Published by Blue Eyes Intelligence Engineering and Sciences Publication (BEIESP). This is an open access article under the CC BY-NC-ND license (http://creativecommons.org/licenses/by-nc-nd/4.0/) environmental impacts could also be a prerequisite for sustainable irrigated agriculture (2).

One of 13.2 billion hectares of cultivated areas on Earth, like about $7.5 \%$ of the world is roofed with saline and sodic soils, also between twenty-five to thirty percent of cultivated areas are salt-affected and commercially unproductive (3). Many cultivated areas suffering from an increased groundwater table and salinity of soil in the Middle East. The explanations for this need irrigation practices, increase evaporation rates, and a rise in groundwater salinity (4). In Egypt, about a million ha (33\%) of the entire irrigated cultivable lands along the Nile are salt-affected (5).

Observing and early notice of salinization is in critical requirement for the reasonable turn of events. Checking is expected to permit the taking of legitimate and convenient choices towards altering the board practices or undertaking recovery and restoration endeavors (6). In saline soil zones, data on the degree and size of soil saltiness is required for better arranging and usage of viable soil recovery programs (7). In enormous zones, the traditional soil saltiness overview techniques (soil inspecting and investigations in research centers) are generally costly and tedious (8). These days, to conquer these issues and to aid saltiness mapping both in a brief timeframe and with hardly any assets, propelled techniques Remote Sensing (RS) and Geographic Information Systems GIS have been utilized as a proficient device for the evaluation of characteristic assets (9). Announced that distinctions in surface reflectance help us to recognize salt-influenced soils and non-influenced ones (10), (11), (4). Initially, an agent set of soil tests are taken for research facility judgments, including soil saltiness. At that point, a various relapse examination is utilized to anticipate soil saltiness level and to choose of the most associated unearthly groups of satellite RS with the deliberate soil saltiness.

Soil saltiness mapping has advanced from subjective to quantitative by various fleeting and multi-ghastly data acquired from RS perceptions. there's a high connection between is soil reflectance and various other soil properties. the most factors influencing the reflectance are amount and mineralogy of salts, dampness substance, shading, and surface unpleasantness (12) Reported that saltiness mapping is frequently practiced by different methods coordinating RS and GIS at expansive and little scopes (4). Saltiness mapping and checking utilizing RS and GIS are regular in numerous nations.

Published By:

Blue Eyes Intelligence Engineering DOI: 10.35940/ijeat.E9765.069520

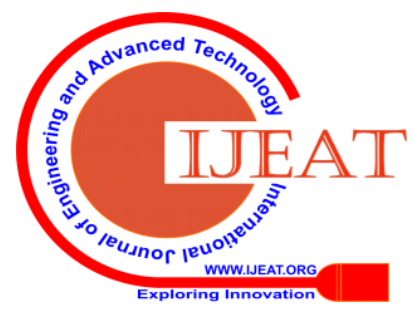


Utilizing RS and GIS methods to outline saline soils has demonstrated to be productive in numerous investigations. reasoned that Landsat is regularly wont to recognize saltiness highlights while joining broad ground information (13). Landsat Thematic Mapper (TM) and Sodium Absorption Ratio (SAR) information are the easiest at recognizing saline, antacid, and non-saline soils (14).

The Landsat TM groups 5 and 7 are much of the time wont to identify top surface saltiness (15).

Few examinations utilized exceptionally high spatial goals (VHS), for example, the QuickBird and the IKONOS symbolisms to survey soil saltiness utilizing an assortment of vegetation files (16). They revealed that the utilization of high spatial goals information regularly delivers preferred outcomes over medium spatial goals in mapping soil saltiness. Furthermore, hyperspectral information, for instance, Hyperion EO-1, has become a promising wellspring of information for mapping soil saltiness since it gives enormous unearthly goals and can measure soil saltiness. In enormous zones, the restricted accessible hyperspectral information assets brought about challenges in mapping soil saltiness. Demonstrated that up until this point, no exploration has surveyed the soil saltiness inside the tropical and semi-tropical territories (16), particularly in delta districts where soil salinization has gotten progressively extreme because of the ocean level ascent results from worldwide environmental change. one of the clarifications for the deficiency of research may be because of overcast spread. Mists happen most habitually over the tropics, making it hard to utilize the optical remotely detected information for mapping soil saltiness. In this way, radar pictures are thought of. The key issue when utilizing radar pictures for soil saltiness mapping is that the radar backscattering is delicate to the dielectric steady. Consequently, radar sensors transmit microwave vitality, so measure the quantity of vitality backscattered from the soil without being impacts of climatic and fleeting conditions.

When utilizing RS to evaluate soil properties, it ought to be noticed that the relationship between soil properties and satellite information may be higher at coarser goals (17), (18). While talking about the remote detecting of saline soils, one must recognize saltiness at the soil surface and saltiness in the soil root zone. Soil root zone saltiness influences plant development, and it is the saltiness marker of most noteworthy enthusiasm for horticultural appraisals (19).

In India, Landsat Multispectral Scanner and TM data were used to guide and screen saline soils (20). Likewise showed that in India, the use of satellite remote detecting for the investigation of saline soils depends for the most part on information procured from Landsat 1, 2, 3, 4, 5, and 7, Indian Remote Sensing Satellite System (IRS) arrangement, and SPOT (Systeme Pour l'Observation de la Terre) (21). Demonstrated that during ongoing years, utilizing satellite symbolism for mapping and checking soil saltiness has been coordinated with multi-ghostly sensors (12). A methodology joining Landsat TM information changed with the profundity and mineralization pace of groundwater was applied to outline saltiness in China (11). In the semiarid districts of the United States and Mexico fringe zones, applied order, unearthly extraction, and coordinating procedure to find various types of salts and their instances of event (21). In Pakistan, an examination was guided by utilizing satellite pictures to develop a solid strategy for depicting overflowed saltiness (22). In Morocco was utilized Landsat TM picture to delineate saltiness through structure a semi-experimental model by utilizing remote detecting information and Electrical Conductivity (EC) field estimations (23). In Iraq was additionally applied Landsat TM picture for saltiness mapping, evaluation, and track changing with reality (24). The consequences of this examination uncovered that the created saltiness models can foresee saltiness with high precision of $82.57 \%$. Mapped soil saltiness interruption in the Ben Tre area situated on the Mekong River Delta of Vietnam utilizing SAR C-band information (21). The reason that the SAR may be wont to delineate saltiness for Delta regions and help ranchers and in this manner the policymakers to settle on appropriate harvest types inside the setting of environmental change.

In Egypt utilized vegetation files and decorated top changes to foresee and screen saltiness event from changes in surface qualities and from changes in radiometric warm temperature, and connected increasing speed of saltiness danger to a particular year (25).

In 2013 utilized Landsat TM 5 picture for mapping soil saltiness in Sinai of Egypt (26). Electrical conductivity for top surface examples was estimated at explicit ground areas. At that point, Landsat TM 5 picture gained in 1991 that canvassed a tight strip in Sinai was wont to gauge the mean reflectance pixel esteems at these ground areas. Group proportions were created from the at first reflected vitality groups (TM1-5 and 7) to pick the appropriate groups to foresee soil saltiness. a significant relationship was found between the backward of Landsat groups 1, 2, and 7 and furthermore the deliberate EC esteems.

Tina plain territory of North Sinai creating venture speaks to a significant region for the potential development of horticultural land in Egypt. When all is said in done, saltiness mapping and checking plan must be a piece of any venture managing the utilization of water system water with saltiness and sodicity segment. The soil surface in the Tina Plain region fluctuates from sand to overwhelming earth (27). In the overwhelming mud territories of Tina Plain, the issue of saltiness and sodicity builds each year because of auxiliary salinization. Sodic soils have unnecessary degrees of sodium $(\mathrm{Na}+)$. Saline soils are identified by chlorides of sodium, calcium, and magnesium, similarly as carbonate salts. While sodic soils are identified with the closeness of another salt kind in the soil like sodium carbonate (Na2CO3) or sodium bicarbonate (NaHCO3) that show up differentiate from the other saline soils. Sodic soils develop a caramel dim frame that is achieved by the dissipating of normal issues. Soil sodicity causes the debasement of soil structure on account of soil dissipating and poor physical structure. The saline-sodic overpowering mud soil has especially enunciated developing and contracting traits. Earth soils will, as a rule, be plastic and tenacious when wet, to contract on drying, and to develop wetting (28). These characteristics realize soils with low value and inconvenience to be explored with traditional checking techniques of soil saltiness considering soil testing and examinations in labs despite being too exorbitant and repetitive.

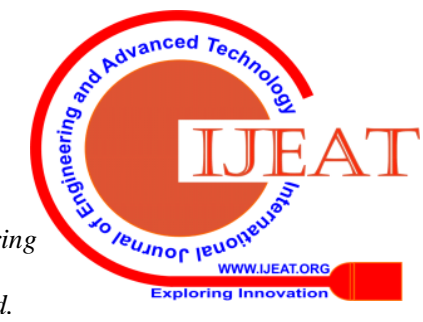


Subsequently, there is a need to look at the new techniques and present-day systems in anticipating and checking soil saltiness in this Soil to take guarded measures against further debilitating of the Soil. The current examination is completed to research two of the cutting edge procedures for mapping of overwhelming soil salt-influenced soils in the Tina Plain

Area to direct partners and policymakers for the determination of fitting innovation to suit their requirements and spending plan. The main strategy is applying remote detecting for appraisal and mapping of the soil saltiness by the coordination of potential information got from field perceptions and satellite pictures utilizing GIS and remote detecting programming. The subsequent one is Geo-factual investigation through spatial examination and introduction utilizing GIS.

\section{METHODOLOGY AND DATA COLLECTION}

\section{A. Study area}

The investigation was led in a test field of saline-sodic overwhelming mud soil of Tina Plain Area. Tina Plain Area is one of the three locales of the recovery zones under El-Salam canal with a territory of around 21,000 ha (Figure 1 ). The soil saltiness in most of the region is gone somewhere in the range of 100 and $125 \mathrm{dS} / \mathrm{m}$ (29). The trial field has a real territory of 300 ha (around 718 Feddans where 1 Feddan $=0.42$ ha). It is situated in the western piece of Tina Plain zone as appeared in (Figure 1).

\section{B. Data collection}

The work comprised of field examining, substance investigation in the research center, and relapse examination for the information. Field visits (multiple times) were directed in the zone during August 2017 to take surface soil tests from 38 locales covering the whole zone of the examination (Figure 1). For each site, the geographic location was determinate by GPS was finished. Saltiness for the investigation territory, communicated in electrical conductivity EC (dS/m) values, was found as point information to speak to the qualities at the inspecting areas as spoke to in (Figure 2). Stepwise Regression assessment was tested. The purpose of this perceptive showing procedure is to enhance the desired power with the base number of pointer factors. In this technique, a customized strategy is used to pick independent components. Three unmistakable sorts of models were breaking down including Standard stepwise, in turn around, and forward backslide models. These model decision sorts consolidate a couple of options that were in like manner examined, including the measures used to enter or remove terms from the model, whether or not to oblige certain terms into the model or to recall certain terms for the basic model, the chain of the significance of the models and normalizing the $\mathrm{X}$ factors in the model. It was found that the Standard Stepwise backslide model is apparently the best philosophy under this condition since it grants terms to be entered at one phase anyway to be emptied later, dependent upon what various terms are associated with the model.

In this research, Sentinel-2A optical imaging satellite data were also used to map soil salinity. The Sentinel-2A optical imaging satellite contained 13 spectral bands and with $10 \mathrm{~m}$ spatial resolution. The data were acquired on the second of August 2017, alongside field observation data which are provided for salinity estimation.

Satellite information trademark is likewise introduced in (Table 1). The Landsat 8 has nine extraordinary gatherings with a spatial objective of $30 \mathrm{~m}$ for Bands 1 to 7 and 9 for pictures. The objective for the Band 8 is $15 \mathrm{~m}$. Landsat 8 Operational Land Imager (OLI) and Thermal Infrared Sensor (TIRS) information procured on 14 August 2017 (Path 176 and Row 038) was utilized in this examination as this date is the closest date of gathering soil tests. The picture was get from the Earth Explorer through the U.S. Topographical Survey at https://earthexplorer.usgs.gov. Table 1 delineates the Details of gained Landsat information.

Notwithstanding the past two satellite pictures, SAR Interferometric Wide-Swath Mode (IW) picture was utilized for the examination territory. It was gotten from the European Space Agency (ESA) Copernicus Sentinels Science center (https:/scihub.copernicus.eu/). Sentinel-1B secures pictures over a $250 \mathrm{~km}$ area at $5 \mathrm{~m}$ by $20 \mathrm{~m}$ spatial goals in the IW. The Sentinel-1B SAR information procured on 14 August 2017 was utilized in light of the fact that it coordinated the dates of the field studies. The picture was gained and handled to the standard Level-1 ground run recognized configuration (10 m goals) and in two double energized, VV and VH. The ESA's Sentinel Application Platform (SNAP) tool kit rendition 6.0 was utilized to process the Sentinel-1B SAR information. This pre-owned application tool stash is accessible at http://step.esa.int/fundamental/tool stash/snap.

\section{Methods}

The Landsat 8 picture was enlisted to the Universal Transverse Mercator (UTM) Projection utilizing a few very much appropriated ground control focuses (GCPs) acquired from 1:50 000 topographic maps. A subset picture covering the limits of the examination zone was made. At this subset picture, the crude computerized numbers were changed over to brilliance, and afterward, the brilliance changed over to reflectance esteem. Connection lattices were utilized to investigate the connection between the deliberate soil saltiness and the (OLI) reflectance information. The relapse connections were produced between the individual band readings and the soil saltiness.

The Sentinel-2 information pictures that were gained for saltiness appraisal was accessible in the Level-1C (L1C) preparing level (top-of-environment (TOA) reflectance in cartographic geometry). These items should then be changed over into a Level-2A (L2A) ortho-picture base of climate revised reflectance item appropriate for relapse examination. Pre-preparing of L1C items was performed by scene characterization and climatic adjustment, which gives L2A items (30). This was applied by Sen2Cor. It is a processor for Sentinel-2 Level 2A item age and designing. Sen2Cor makes Bottom-Of-Atmosphere, extra, Aerosol Optical Thickness, alternatively landscape and cirrus revised reflectance pictures, Scene Classification Maps,

Published By:

Blue Eyes Intelligence Engineering

\& Sciences Publication

(C) Copyright: All rights reserved.

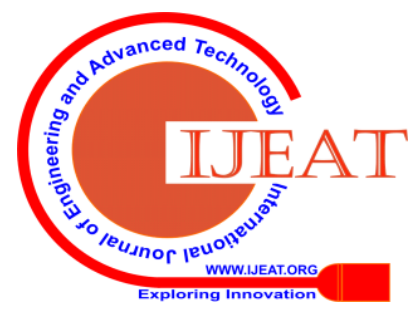


Water Vapor and Quality Indicators for cloud and snow probabilities. Its yield item position is equal to the Level 1C User Product JPEG 2000 pictures with three distinct goals, 60,20 , and $10 \mathrm{~m}$. The processor for Sentinel-2 L2A item age and designing was created by (31). Sen2Cor establishment bundles are given as independent installers,

which are accessible at https://step.esa.int/primary/outsider modules 2/sen2cor/.

The pre-handling of the Sentinel-1B IW GRDH (Ground Range Detected in High goals) information was brought out through the use of the exact Sentinel-1B circle, which assists with improving the geolocation precision, at that point utilizing the Sentinel Application Platform (SNAP) programming (32). At that point, the groups, $\mathrm{VV}$ and $\mathrm{VH}$, are radio-metrically adjusted to gamma-nothing backscatter, $\gamma^{0} \mathrm{VV}$, and ${ }^{\gamma_{0}} \mathrm{VH}$. This alignment was applied to determine dependable radar backscattering coefficients.

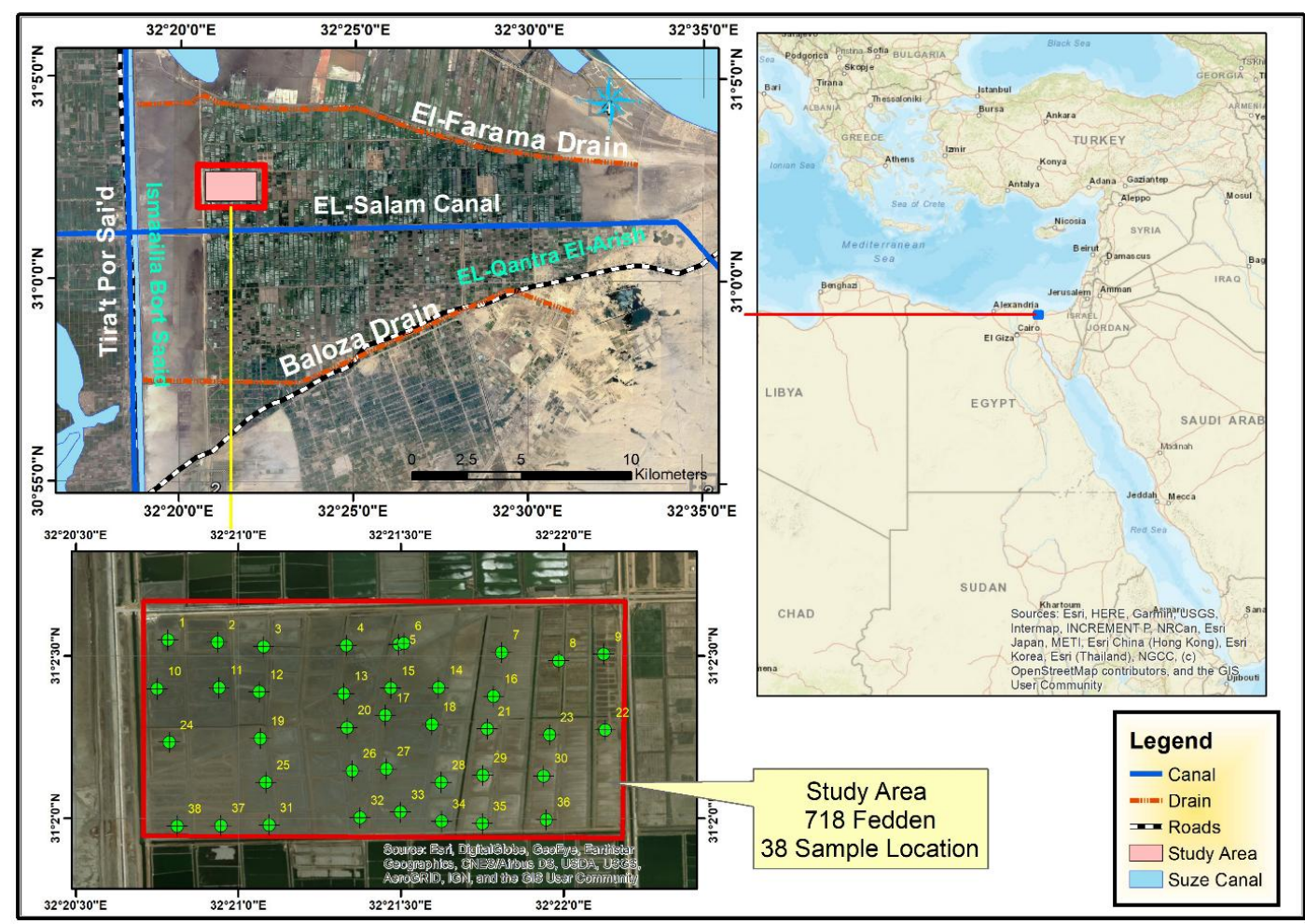

Figure 1: Location of the Pilot Area in El-Salam Canal Project.

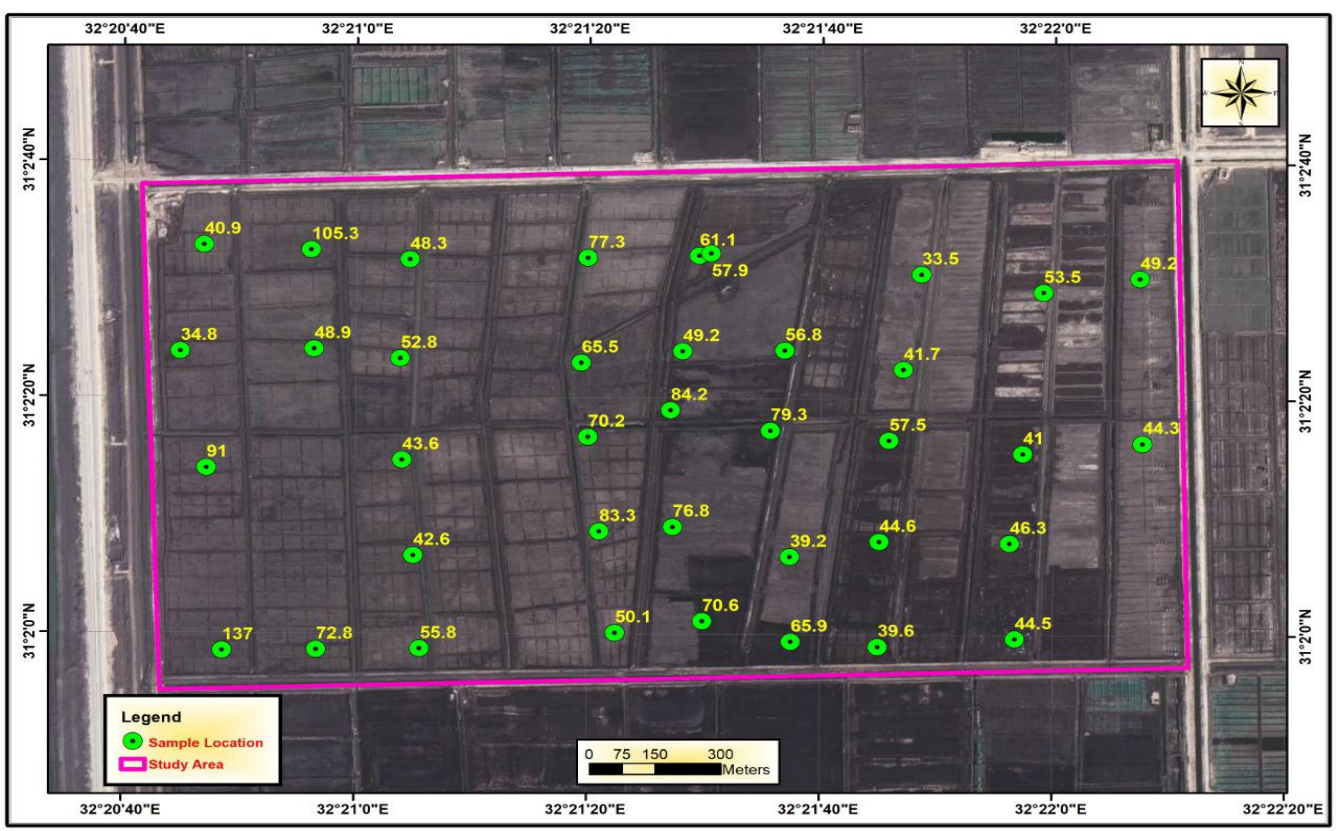

Figure 2:Samples locations and measured soil salinity (dS/m).

Published By:

Blue Eyes Intelligence Engineering \& Sciences Publication

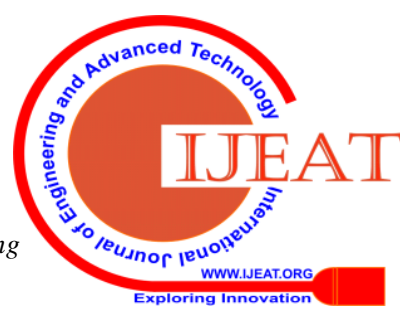


Table 1:Details of acquired satellite data

\begin{tabular}{|c|c|c|c|c|c|c|c|}
\hline Satellite & Solar angle & $\begin{array}{c}\text { Land cloud } \\
\text { cover (\%) }\end{array}$ & solar azimuth & $\begin{array}{c}\text { Pixel } \\
\text { size }\end{array}$ & Path/row & Scene ID & $\begin{array}{c}\text { Acquisition } \\
\text { date }\end{array}$ \\
\hline $\begin{array}{c}\text { Landsat } \\
\text { 8-(OLI)/ } \\
\text { (TIRS) }\end{array}$ & 63.26829178 & 3.25 & 121.76565325 & 30 & $176 / 39$ & $\begin{array}{c}\text { LC8176039 } \\
2017226 L G \\
\text { N00 }\end{array}$ & $2017 / 08 / 14$ \\
\hline $\begin{array}{c}\text { SENTIN } \\
\text { EL-2A }\end{array}$ & $\begin{array}{c}21.60848943 \\
30288\end{array}$ & 0.2651 & $\begin{array}{c}124.22705936 \\
3458\end{array}$ & $\begin{array}{c}10,20, \\
60\end{array}$ & - & $\begin{array}{c}\text { L1C_T36R } \\
\text { VV_A01102 } \\
\text { 9_20170802 } \\
\text { T083801 }\end{array}$ & 2017/08/02 \\
\hline
\end{tabular}

For the recently gained information, a factual examination was completed utilizing Minitab programming. Unmistakable Statistics (proportions of focal propensity incorporate the mean, middle, and mode, while proportions of fluctuation incorporate the standard deviation, difference, the base, and greatest factors); typicality test and anomaly test were applied before begin applying various relapses. The picture preparation methods were performed utilizing ENVI 5.3 programming. The maps of the corresponded parameters were made in ArcGIS programming.

The second goal of this examination is to explore utilizing of Geo-statistical methods to anticipate the spatial conveyance of soil saltiness. Geo-statistical method is utilized for mapping of surface highlights from restricted example information and estimation of qualities at un-inspected areas. One of the strategies for Geo- statistical is Kriging. Interjection calculations, for example, kriging, gauge the incentive at a given un-examined area as a weighted entirety of information esteems at encompassing areas. Normally, both the normal worth and change are figured for each un-examined area inside a district. Ordinarily utilized Kriging strategies are conventional kriging, basic kriging, and all-inclusive kriging. Customary kriging is the most as often as possible utilized kriging technique. It relies upon the speculation that the mean is consistent anyway cloud over the entire district of interest. The customary kriging process comprises of three fundamental advances including the development of an exploratory semi-variogram from field information, determination of a suitable semi-variogram model, and estimation of the qualities at un-inspected areas utilizing the weighted normal of neighboring examples (4).

The semi-variogram is a key component of spatial insights for statistics, which communicates the spatial relationship of parameters. Statistical programming bundles are currently ordinarily used to process the information, create trial semi-variogram plots, and select and fit semi-variogram models. Geostatistical Analyst is one of the statistical programming bundles under GIS. It is an augmentation of Arc Map, which gives an amazing assortment of devices for the administration and representation of spatial information. It is an adaptable programming bundle that permits any client with spatially consistent information to investigate and break down their information utilizing statistical devices and insert ideal surfaces (33).

Geo-statistical Analyst statistical programming was utilized in the examination zone to anticipate Electrical Conductivity (EC) values at inspected areas and to make spatial appropriation maps of the soil saltiness. The limit of the zone was digitized utilizing the polygon shapefile. The geographic areas for Longitudes and Latitudes of the inspected destinations were embedded as an essential separate layer and a database table containing the consequences of the soil examples was made. The spatial examination was applied dependent on the introduction and surface investigation techniques. At that point a raster layer containing the characterized spatial dissemination map for the soil saltiness was extricated.

A portion of the tested information was utilized to approve the Geo-Statistical Analyst anticipated estimations of soil saltiness. The approval procedure was directed by evacuating some portion of the deliberate information and utilizing the remainder of the information to anticipate the expelled part. The principal bunch comprised of $75 \%$ of the deliberate information, and it was utilized to plot the dissemination maps of the components. The subsequent gathering, $25 \%$ of the information that was anticipated by the model, was contrasted with field-estimated information with approving the model as an expectation device. The level of the blunders between the actual estimated soil saltiness (ASS) and predicted soil saltiness (PSS) was completed to check the exactness of the anticipated model as follow:

$$
\begin{gathered}
\text { Diff }=\text { PSS }- \text { ASS } \\
\text { Error } \%=\left(\frac{\sqrt{\sum(\text { Diff. })^{2}}}{n}\right) / \text { avg.ASS }
\end{gathered}
$$

\section{RESULTS}

The acquired images were processing and statistically analyzed. For every sample location the cell digital number (DN) values for every band of the pictures were extracted to the attribute table of sample locations. then all data from the attribute table convert to an excel file.

The mean for every one of the reflected vitality groups was utilized as autonomous factors inside the relapse models. The relapse models of ward soil variable (EC) and free found band factors were created utilizing Minitab programming. Stepwise relapse was applied, which is a programmed device used in the exploratory phases of model structure to detect a valuable subset of indicators, and furthermore the best free factors were chosen.

Published By:

Blue Eyes Intelligence Engineering

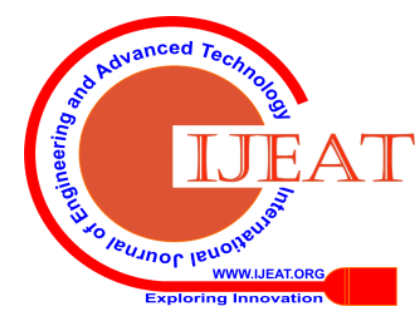


Interrelation degree can be evaluated between groups, groups proportion, and EC, the connection coefficients are utilized. Various models from various band's proportion blends were created. These models were analyzed dependent on estimations of connection of assurance $\left(R^{2}\right)$, balanced $R^{2}$, and p-value. The best statistical relationship for the deliberate soil saltiness and the reflectance estimation of the satellite pictures are spoken to by Equation 1, 2, and 3 for Landsat 8, Sentinel-2, and Synthetic Aperture Radar separately. Table 2 shows the Model outline of soil EC land information.

$$
\begin{aligned}
& \mathrm{EC}=474-1245(\mathrm{~b} 5)-41.0(1 / \mathrm{b} 6) \quad \text { with } \mathrm{R}^{2}=31.48 \% \\
& \mathrm{EC}=-388+0.0925 \mathrm{~B} 11+3845701 / \mathrm{B} 6 \text { with } \mathrm{R}^{2}=37.38 \% \\
& \mathrm{EC}=46.23+362.7 \mathrm{VV}-1560 \mathrm{VH} \quad \text { with } \mathrm{R}^{2}=31.29 \%
\end{aligned}
$$

Figure 3 for parts a, b, c shows the maps for the dissemination of soil saltiness in the examination zone made in ArcGIS programming dependent on Landsat 8, Sentinel-2, and Synthetic Aperture Radar separately. These maps show that the soil saltiness is higher in the western southern piece of the region than different sides. The estimations of soil saltiness EC extend between $43 \mathrm{dS} / \mathrm{m}$ and $67 \mathrm{dS} / \mathrm{m}$ with a normal of $58 \mathrm{dS} / \mathrm{m}$.

Table 2:Models summary

\begin{tabular}{|c|c|c|c|}
\hline Satellite & R-sq & R-sq (adj) & P-Value \\
\hline $\begin{array}{c}\text { Landsat 8-(OLI)/ } \\
\text { (TIRS) }\end{array}$ & $31.48 \%$ & $27.57 \%$ & 0.001 \\
\hline SENTINEL-2A & $37.38 \%$ & $33.80 \%$ & 0.001 \\
\hline $\begin{array}{c}\text { Synthetic } \\
\text { Aperture Radar } \\
\text { Sentinel-1B }\end{array}$ & $31.29 \%$ & $27.13 \%$ & 0.002 \\
\hline
\end{tabular}

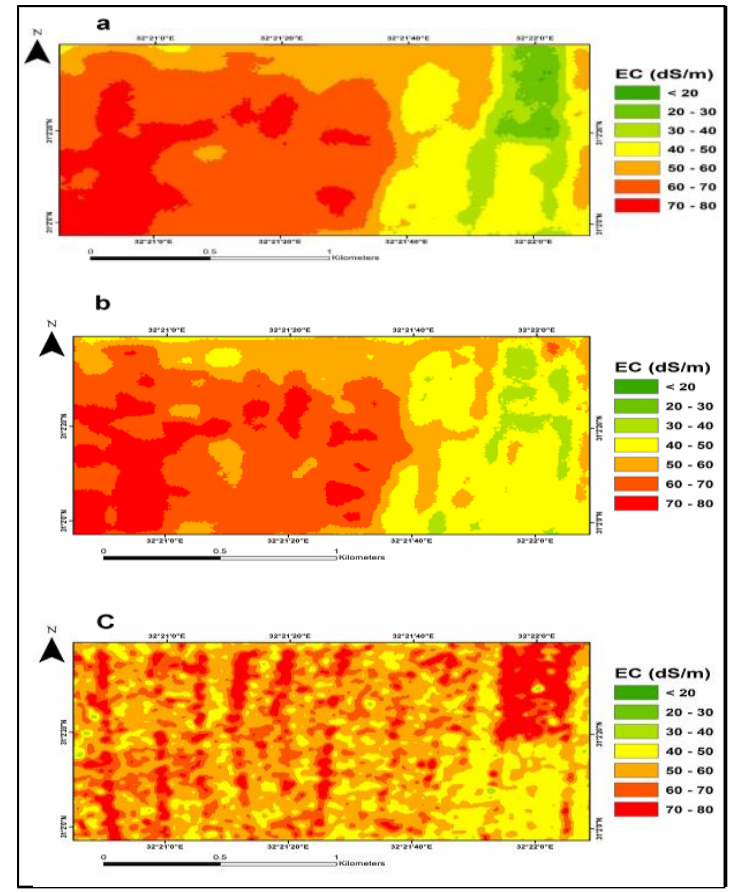

Figure 3:Cartographic maps of the soil salinity obtained from Landsat 8 (a), Sentinel-2 (b), Synthetic Aperture Radar (c)
Besides, the information was examined and Geo-statistically broke down utilizing Geo-Statistical Analyst. The Geo-statistical investigation of the information was done in two primary advances. The initial step is investigating the really estimated soil saltiness to foresee the qualities at those areas which have not been inspected and the subsequent one is making the saltiness map.

The deliberate information was investigated to set up the consistency of qualities in the examination territory. Numerous kinds of additions in ArcGIS Geo-Statistical Analyst were applied to incorporate, deterministic techniques (Inverse Distance Weighting IDW, Global Polynomial GPI, and Radial Basis Functions RBF), Geo-statistical methods (Kriging, Areal Interpolation and Empirical Bayesian Kriging) and Interpolation with barriers (Kernel Interpolation). The best results were achieved by using kriging method. The results were checked using universal kriging, simple kriging and ordinary kriging. The ordinary kriging gets the best Root-Mean-Square.

The three diverse semivariogram models in the kriging method were tried for the watched information. These semivariogram models are exponential, Gaussian, and round. It was discovered that the circular model is the nearest to the focuses. This outcome in a semivariogram chart (appeared in Figure 4) which models the distinction between an incentive at one area and the incentive at another area as indicated by the separation and course between them.

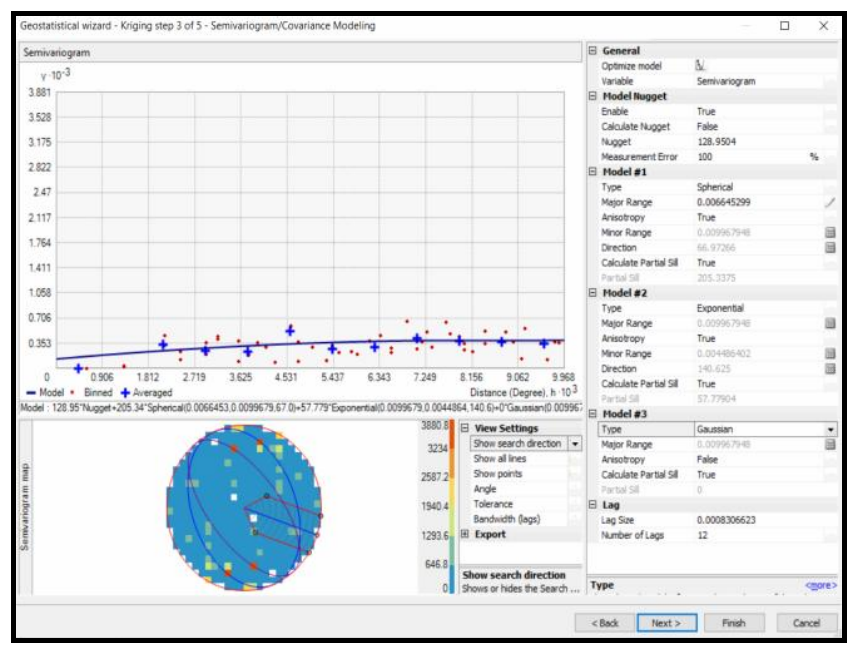

Figure 4:Empirical semivariogram

The cartographic map of the soil salinity as obtained from the GIS interpolations is shown in Figure 5. This map shows also that the soil salinity is higher at the western southern part of the area than the other sides. The values of soil salinity EC ranges between $45 \mathrm{dS} / \mathrm{m}$ and $68 \mathrm{dS} / \mathrm{m}$ with an average of 56 $\mathrm{dS} / \mathrm{m}$.

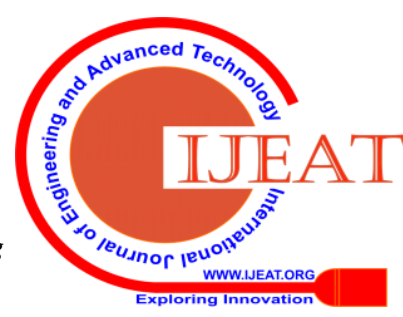




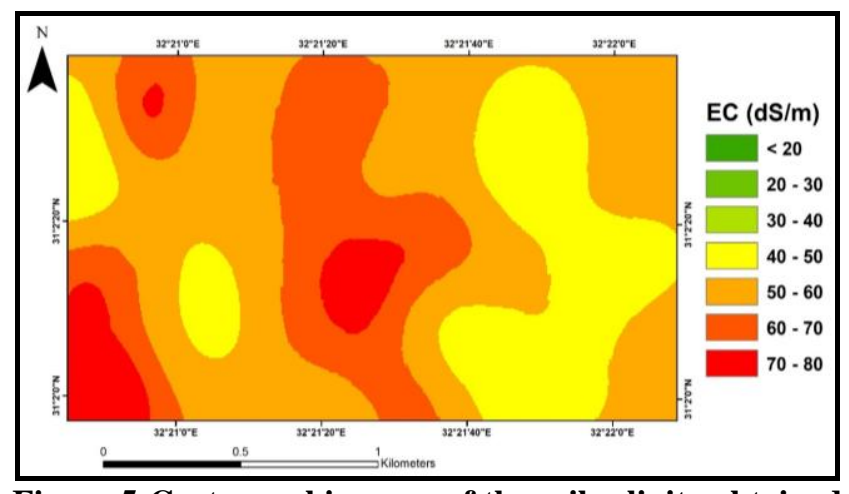

Figure 5:Cartographic maps of the soil salinity obtained from GIS interpolations

\section{DISCUSSION}

The performance of Landsat 8, Sentinel-2A optical imaging satellite and SAR C-band data was evaluated to outline saltiness by mapping in the Tina Plain zone of Sinai. The presentation of the three Remote Sensing models was evaluated and looked at utilizing the connection coefficient $\left(\mathrm{R}^{2}\right)$. The outcomes uncovered that the Sentinel-2A optical imaging satellite yielded the most elevated expectation execution with a coefficient of determination $\left(\mathrm{R}^{2}\right)$ between the needy variable (EC) and the free band factors equivalent to $37.38 \%$. In any case, this created relapse model isn't sufficient in contrast with the past investigation directed to delineate saltiness in a limited strip in the Sinai Peninsula of Egypt utilizing remote detecting. Direct relapse model was produced for soil saltiness mapping, $\mathrm{y}=\mathrm{c} 1+\mathrm{c} 2(1 / \mathrm{TM} 1)+$ c3(1/TM2) + c4(1/TM7), $\mathrm{R}^{2}=0.72$. A soil saltiness map was set up by applying this condition to the converse of Landsat groups 1, 2, and 7 (26).

In 2016, an examination in Wonji sugar stick water system ranch, Ethiopia to quantify the Statistical connection between field estimations of electrical conductivity (EC) and remote detecting phantom lists. Six chose remote detecting records, for example, saltiness index (SI), standardized contrast saltiness list were utilized to segregate and guide salt-influenced soils (7). For this examination, Landsat TM information (2012), way 168, and column 054 were utilized. The saltiness file was determined as the proportion of the red band to the near infrared (NIR) band. The outcomes demonstrated that the saltiness index (SI) had the most elevated relationship with EC. Consolidating these remotely detected and EC factors into one model yielded the best fit with $\mathrm{R}^{2}=0.78$.

On the other hand, endeavor to survey the degree of saltiness in Sego inundated homestead (2), Ethiopia, and guide the fleeting and spatial conveyance of salt-influenced soils to help the programs. To delineate saltiness, utilizing geospatial instruments, ordinary picture arrangement was utilized and creating models from EC versus NDSI and topical layers. To recognize saltiness influenced zones in the examination region, Multi-fleeting Landsat TM pictures of 1984, 1995, and 2010 were utilized. Aftereffects of the investigation uncovered that the exact model created from EC versus NDSI of 2010 picture utilizing relapse examination uncovered the coefficient of connection as $66 \%$.

Low measured coefficient of determination $\left(\mathrm{R}^{2}\right)$ between the variable of (EC) and the autonomous groups factors in this investigation could be ascribed to the absence of explicit ingestion groups of some salt kinds which existed in saline-sodic clayey soil of the zone and inconstancy of saline soils in the existence. This could be improved later on by utilizing satellite sensor information with high resolution.

By applying the approval procedure for the Geo-Statistical Analyst anticipated estimations of soil saltiness, it was discovered that the mistake rate is equivalent to $4.28 \%$. In 2009, an investigation to utilize Geographic Information System (GIS) to in-follow and anticipate the soil saltiness by applying statistical examination inside GIS by utilizing Geo-Statistical Analyst (29). It was discovered that the mean qualities for the deliberate and anticipated information are near one another. The distinction between them is almost zero. The blunder rate was equivalent to $14 \%$. In this way, the mistake rate in the present contextual investigation is considered as a minor blunder and could be acknowledged.

It is obvious from the results that the optical remote sensing images reflectance data can be used to map soil salinity. However, additional investigations are still needed in different times of the year and under different conditions in order to develop the generalized models. On the other hand, it is undoubted that the application of the Geo-Statistical Analyst for spatial soil salinity exploration, prediction and maps creation add very important practical and economical value which results of reducing the number of the observed samples.

\section{CONCLUSION}

Large areas that are concerned in the salinity problems in many regions make it difficult for the researchers and scientists to take frequent soil samples from the investigated areas. Using of the remote sensing and Geo-statistical analysis techniques can help to predict and foresee the sensitive areas and optimize the number of sampling locations. In this study the remote sensing and Geo-statistical analyst techniques has been investigated to map saline clayey soils of Tina Plain Area in Egypt. The remote detecting and Geo-statistical examination seem to offer a few preferences over regular inspecting techniques used to guide and screen the soil saltiness. They give minimal effort and extensive precision approaches for quantitative checking of the soil salinization in a huge zone. Our examination shows the viability of RS and Geo-Statistical Analyst models in anticipating the soil saltiness with reliable precision.

Three models representing the link between the soil saltiness and value of the satellite image were developed using Landsat 8, Sentinel-2A optical imaging satellite and SAR C-band data with coefficient of determination $\mathrm{R}^{2}$ equal to $31.48 \%, 37.38 \%$ and $31.29 \%$ respectively. This low accuracy of the detection of the saline sodic clayey soils may be attributed to various causes, counting the absence of explicit assimilation groups of some salt kinds in this soil, constrained accessibility of the satellite sensor information with high resolution, and inconstancy of saline soils in place and time.

\section{Published By:}

Blue Eyes Intelligence Engineering

\& Sciences Publication

(C) Copyright: All rights reserved. 
On the other hand, the Geo-Statistical Analyst was successfully used to predict and map the saline-sodic clayey soils with an error percentage equals to about $4.28 \%$, which is considered as minor error. Therefore, integrated analysis of the measured samples locations and non-measured locations with the Geo-Statistical Analyst environment must be considered as a viable tool for continuous monitoring of the soil salinity in the saline sodic clayey soils. It could be concluded that the Geo-Statistical Analyst is preferred on the case of the availability of soil sampling and analyses in laboratories to predict values at those locations which have not been sampled.

Finally, the Remote Sensing and Geo-Statistical Analyst should be considered by decision-makers and landowners as a quality, cost, and time-controlled strategies expected to decide the degree of the soil saltiness. This helps to make decisions about land use and develop salinity mitigation strategies

\section{REFERENCES}

1. Elhag, Mohamed, (2016). Evaluation of different soil salinity mapping using remote sensing techniques in arid ecosystems Saudi Arabia. J. Sens., 101155/2016/7596175.

2. Shegena Zewdu, K.V. Suryabhagavan and M. Balakrishnan, (2017). Geo-spatial approach for soil salinity mapping in Sego Irrigation Farm, South Ethiopia. Journal of the Saudi Society of Agricultural Sciences (2017) 16, 16-24. https://doi.org/10.1016/j.jssas

3. DRI (Drainage Research Institute), (2001). Reclamation, improvement, management of clay soils for optimal crop production. DRP 2 technical report TR 118. Drainage Research Institute, El Kanater, p 105

4. Shahid, S. A., (2013). Developments in Soil Salinity Assessment, Modeling, Mapping, and Monitoring from Regional to Submicroscopic Scales, pp 3-43. In: Developments in Soil Salinity Assessment and Reclamation: Innovative Thinking and Use of Marginal Soil

5. Abdel-Fattah K. Mohamed and El-Naka A. El-Sayed, (2015). Empirical approach of leaching curves for determining the efficiency of reclaiming saline-sodic soils in Sahl El-Tina, Sinai, Egypt. International Journal of Plant \& Soil Science, 2015, 8(3): 1-9, 2

6. Bilgili, A.V., Cullu, M.A., Van Es, H.M., Aydemir, A., Aydemir, S., (2011). The use of hyperspectral visible and near infrared reflectance spectroscopy for the characterization of salt-affected soils in the Harran plain, Turkey. Arid Land Resources Manage

7. Asfaw, E., Suryabhagavan, K.V., and Mekuria Argaw, (2016). Soil salinity modeling and mapping using remote sensing and GIS: The case of Wonji sugar cane irrigation farm, Ethiopia. Journal of the Saudi Society of Agricultural Sciences (2016), http://dx.doi

8. Robbins CW. and Wiegand CL, (1990). Chapter 10: Field and laboratory measurements. In: Tanji KK (ed.) Agricultural salinity assessment and management. American Society of Civil Engineers, New York, pp 201-219

9. Zobeiry M. and Maid AR., (2000). An introduction to remote sensing technology and application in natural resources. University of Tehran, Tehran

10. Howari FM, Goodell PC, Miyamoto SA (2002) Spectral properties of salt crust formed on saline soils. J Environ Qual 31:1453-1461. doi:10.2134/jeq2002.1453

11. Shrestha D. P. and Farshad A., (2008). Mapping Salinity Hazard: An Integrated Application of Remote Sensing and Modeling-Based Techniques, pp. 257-272. In: Remote Sensing of Soil Salinization: Impact on Land Management.

12. Gorji Taha, Aysegul Tanik and Elif Sertal, (2015). Soil Salinity Prediction, Monitoring and Mapping Using Modern Technologies. Procedia Earth and Planetary Science 15 (2015) 507-512. doi: 10.1016/j.proeps.2015.08.062

13. Northrop LJ (1982) Landsat detection of irrigation area salinity. Occasional paper series no 4. Department of National Development and Energy, Australian Water Resources Council
14. Metternicht GB, Zink JA (1997) Spatial discrimination of salt and sodium affected soil surfaces. Int J Remote Sens 18 (12):2571-2586. doi.org/10.1080/014311697217486

15. Dutkiewics A, Lewis M (2008) Broadscale monitoring of salinity using satellite remote sensing: where to from here?, 2nd International Salinity Forum, Adelaide, Australia, p 6

16. Hoa P. V., Giang N., Nguyen An Binh, Le Vu Hong Hai, Tien-Dat Pham, Mahdi Hasanlou and Dieu Tien Bui (2019). Soil Salinity Mapping Using SAR Sentinel-1 Data and Advanced Machine Learning Algorithms: A Case Study at Ben Tre Province of the Mekong River Del

17. Gomez C, Oltra-Carrio R and Bacha S, (2015). Evaluating the sensitivity of clay content prediction to atmospheric effects and degradation of image spatial resolution using Hyperspectral VNIR/SWIR imagery. Remote Sens Environ 164:1-15. https://doi.org/10.1

18. Miller BA, Koszinski S, Wehrhan M and Sommer M., (2015). Impact of multi-scale predictor selection for modeling soil properties. Geoderma https://doi.org/10.1016/j.geoderma.2014.09.018

19. Scudiero Elia, Dennis L. Corwin, Ray G. Anderson, Kevin Yemoto, Wesley Clary, Zhi "Luke" Wang and Todd H. Skaggs, (2017). Remote sensing is a viable tool for mapping soil salinity in agricultural lands. California Agriculture, Volume 71, No. 4, pp 231-238

20. Dwivedi RS (1992) Monitoring and the study of the effect of image scale on delineation of saltaffected soils in the Indo-Gangetic plains. Int J Remote Sens 13:1527-1536

21. Howari FM (2003) The use of remote sensing data to extract information from agricultural land with emphasis on soil salinity. Aus J Soil Res 41 (7):1243-1253. https://doi.org/10.1071/SR03033

22. Abbas, A., Khan, S., Hussain, N., M.A., and Akbar, S., (2013). Characterizing soil salinity in irrigated agriculture using a remote sensing approach. Physics and Chemistry of Earth, Parts A/B/C, 55-57: 43-52

23. Lhissou, R., El Harti, A. and Chokmani, K., (2014). Mapping soil salinity in irrigated land using optical remote sensing data. Eurasian Journal of Soil Science, 3 (2):82-88. DOI: 10.18393/ejss.84540

24. Wu, W., S. Mhaimeed, A., Al-Shafie W., Ziadat, F., Dhehibi, B., Nangia, V., and De Pauwa, E., (2014). Mapping soil salinity changes using remote sensing in Central Iraq. Geoderma Regional, 2-3:21-31. https://doi.org/10.1016/j.geodrs.2014.09.002

25. Masoud, A.A. and Koike, K. (2006). Arid land salinization detected by remotely-sensed landcover changes: A case study in the Siwa region, NW Egypt. Journal of Arid Environments 66(1): 151-167. https://doi.org/10.1016/j.jaridenv.2005.10.011

26. Ibrahim, H. M. and El Falaky A. A., (2013). Soil Salinity Mapping in the Sinai Peninsula of Egypt Using Geographic Information System and Remote Sensing Techniques, pp 113-125. In: Developments in Soil Salinity Assessment and Reclamation: Innovative Think

27. DRI (Drainage Research Institute), (1997). Salt leaching and land reclamation study, Tina Plain - Sinai, Part I and III, Drainage Research Institute, El Kanater

28. Rycroft, David W. and Amer, Mohamed H. (1995). Prospects for the Drainage of Clay Soils, FAO Irrigation and Drainage Paper. FAO, Rome

29. Sallam, G. A. H., and Mohamed Embaby (2009). Geostatistical Analyst as a Tool to Predict Nutrients Pollution in Water. Thirteenth International Water Technology Conference, IWTC 13 (2009), Hurghada, Egypt, pp 1201-1211

30. Sallam, G. A. H., (2017). Comparative Analysis of Using Aquaculture Versus Agriculture Land Reclamation in Saline-Sodic Clayey Soils in Tina Plain Area of Egypt. International Journal of Agricultural Sciences and Natural Resources. Vol. 4, No. 5, 2017

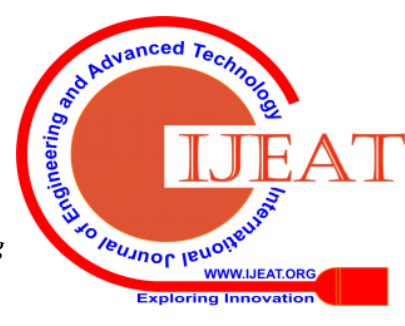




\section{AUTHORS PROFILE}

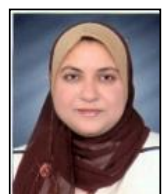

Dr. Gehan Sallam (born in 1967), obtained her Doctorate of Philosophy in Integrated Water Resources Management from Faculty of Engineering, Zagazig University, Egypt. She is working as Associate Professor (Head of Drainage Technology Department), Drainage Research Institute National Water Research Center, Egypt. She had managerial and technical experiences in Artificial Intelligence, Expert Systems, GIS, Integrated Water Resources Management and Environmental Impact Assessment. She is a member of Egyptian Water Partnership, Arab Integrated Water Resources Management Network, World Academy of Young Scientists (Arab States). She has attended many international conferences and workshops and published about 30 scientific papers and 5 chapters in scientific books.

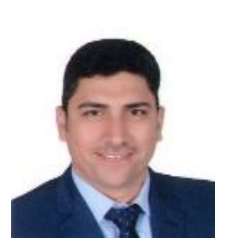

Mohamed Embaby Head of the central GIS unit and researcher at the National Water Research Center, as well as a part-time lecturer in Heliopolis University (HU) and British University in Egypt (BUE). He has 15 years of experience in the field of water resources management and water quality using remote sensing and GIS applications. Dr. Embaby works as a GIS and remote sensing consultant for a number of foreign funded research projects, in addition to local programs in the field of water quality monitoring modelling and assessment, GIS, remote sensing and e-learning. He has a wide experience in developing specialized training programs in the field of Geomatics, Hydro-informatics and land surveying.

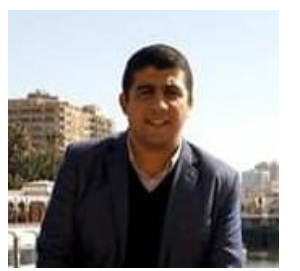

Mohamed Nower Associate Researcher of Irrigation and Hydraulics department of civil Engineering in National water research center (NWRC) in Cairo Egypt. Interested in Energy, management and water sector. Have a special interest in concrete structures. Graduated from Shorouk High Institute, Faculty of Engineering in 2010 grade Excellent with Honor's Degree, 91.07\%, rank $=1 / 480$. Teaching Assistant, Department of Civil Engineering, Shorouk High Institute, Cairo, Egypt. Certificate in project management professional from Canadian academy for science \& technology and Brooklyn academy. "Development of Mix Design Guidelines for Concrete Produced Using Portland cement Types Manufactured According to New Egyptian Standard Specifications," M.Sc. thesis, Faculty of Engineering, Ain Shams University in 2016.

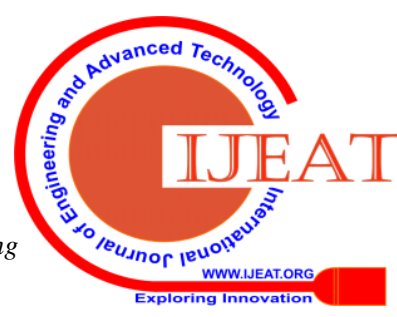

